\title{
Die rol van 'n wetenskaps- en tegnologiebeleid in Suid-Afrika
}

In teenstelling met tegnologiese leierlande, daal Suid-Afrika se reële N\&O-besteding en is die sakesektor se bydrae tot navorsing betreklik laag.

Suid-Afrika, en ook talle ander lande, se navorsingspogings is baie klein in vergelyking met die vyf grotes: die VSA, Japan, Wes-Duitsland, Frankryk en die Verenigde Koninkryk. Onlangse syfers dui byvoorbeeld daarop dat ons totale navorsingsbesteding effens kleiner is as dié van die drie grootste universiteite in die VSA gesamentlik, en aansienlik kleiner is as die $\mathrm{N} \& \mathrm{O}$-besteding van talle Amerikaanse ondernemings soos General Motors, Du Pont en General Electric.

Suid-Afrika se navorsingspoging is egter ook kleiner as die van ander lande wat in die onlangse verlede tegnologies sterk ontwikkel het, soos Spanje, lerland, Korea en Taiwan. Aangesien alle lande uiteraard baie verskil wat ekonomiese grootte betref, is dit ook nuttig om te kyk na die relatiewe belangrikheid van $\mathrm{N} \& \mathrm{O}$ in 'n land, soos weerspieël in die verhouding van totale $\mathrm{N} \& \mathrm{O}$-besteding tot Bruto Nasionale (of Binnelandse) Produk (BBP). Ook hier is dit duidelik dat Suid-Afrika skerp afsteek by belangrike tegnologiese lande.

Selfs wat die gemiddelde groei in totale N\&O-besteding in die eerste deel van die afgelope dekade betref, is ons $\mathrm{N} \& \mathrm{O}$-situasie minder gunstig. Dit is inderdaad duidelik dat ons N\&O-besteding baie goed ooreenstem met tegnologies swakker ontwikkelde lande in die wêreld.

Reële navorsingsbesteding deur belangrike deelnemers op die navorsingsterrein (veral die statutêre wetenskaplike organisasies) daal steeds. In Suid-Afrika is N\&O wat op vervaardiging gerig is van mindere belang, en boonop kry die sakesektor se $\mathrm{N} \& \mathrm{O}$ byna geen geldelike steun van die owerheid nie.

Wetenskaplike en tegnologiese mannekrag in Suid-Afrika toon aansienlike wisseling in benutting, en word toenemend gestrem deur die lae toetrede vanuit die bevolkingsgroepe waaruit die grootste deel van die land se mannekrag bestaan. Die swak beeld van loopbane in wetenskap en tegnologie en die gebrekkige voorbereiding op skoolvlak vir tersiêre studie, is verdere tekortkominge.

Dit is nie voldoende dat navorsing en ontwikkeling en die wetenskap en tegnologie lukraak uitgebrei word nie. Daar moet deeglik aandag geskenk word aan die regte prioriteite in hierdie uitbreidingsaksies. Uit die internasionale ervaring blyk dit dat, wat die wetenskap en tegnologie betref, veral aandag gegee moet word aan die uitbouing van ' $n$ land se produktiewe sektore, sy infrastruktuur, die ondersteuning van besluitneming in alle sektore, en die ont wikkeling van die land se gemeenskappe.

Die uitbouing van produktiewe sektore word as van wesentlike belang beskou, aangesien dit dié sektore is wat in die meeste gevalle die dryfkrag van 'n land se ekonomie is. Hoewel die sogenaamde dienssektore in die meeste lande steeds belangriker word, vervul hulle ondersteunende funksies, en hulle groei is geheel en al, of dan minstens, afhanklik van die groei en welvaart van die sogenaamde produktiewe sektore. Die produktiewe sektore sluit ook die landbou- en mynbousektor in, maar dit is nou duidelik dat die grootste ekonomiese voordeel verkry word uit die uitbouing van die vervaardigingshedryf. In die lande met relatief klein binnelandse markte moet daar veral aandag aan die produksie van uitvoerbare produkte gegee word.

Die bydrae wat die wetenskap en tegnologie kan en moet lewer, is drieledig. Eerstens kan wetenskap en tegnologie 'n belangrike bydrae lewer om die omvang van die waarde wat toegevoeg word tot plaaslik beskikbare of ingevoerde grondstowwe of intermediêre produkte, aansienlik te vergroot. Die ontwikkeling van prosesse om vloeibare brandstow we en chemikalieë uit steenkool te vervaardig, is 'n goeie voorbeeld van hoe wetenskap en tegnologie bygedra het tot die verhoging van die toegevoegde waarde van 'n vrylik beskikbare grondstof.

Tweedens kan die wetenskap en tegnologie 'n baie belangrike bydrae tot die verbetering van die produktiewe bedrywe se gesamentlike vermoëns lewer, deur die land en individuele ondernemings se tegnologiese vlak op te gradeer tot gelykstaande aan die wêreldvlak - of tot selfs beter as die wêreldvlak. Dit word bewerkstellig deur die verkenning, verkryging en, waar nodig, die aanpassing of selfs die aanvulling van die beste beskikbare tegnologie. Die vermoë om met buitelandse verskaffers saam te werk, is net so belangrik vir produksie vir die uitvoermark as vir lewering aan die land se interne gebruikers. Die suurstofbleikproses het die plaaslike pulp- en papierbedryf byvoorbeeld in staat gestel om mededingend in die wêreldmark te kan wees.

Derdens is wetenskap en tegnologie 'n belangrike bydraende faktor tot die verhoging van die land se produktiwiteit. In die owerheids-, sake- en ander sektore in 'n land is al hoe meer kundigheids- en inligtingsinsette nodig om optimale besluitneming te verseker in die ontwikkeling van beleid en strategieë, en selfs vir die meer taktiese en daaglikse bedryfsbesluite.

Ten opsigte van die ondersteuning van besluitneming kan die wetenskap en tegnologie en doelgerigte navorsing en ontwikkeling dus ' $n$ besondere bydrae lewer om te verseker dat die betrokke besluitnemers toegang het tot die beste kundigheid en inligting, en ontledings volgens moderne besluitnemingstegnieke.

Die belangrikste aspek ten opsigte van die nasionale tegnologiestelsel is waarskynlik dat die klem in alle aspekte van wetenskap en tegnologie moet val op die doeltreffende benutting van die geskikste tegnologie vir enige aanwending, ongeag die bron van die tegnologie. In baie lande is bevind dat die aanvanklike gebruik van aangekoopte of nagebootste tegnologie inderdaad die grondslag vorm vir daaropvolgende terugwaartse ontwerp ("reverse engineering"), en uiteindelik tot die ontwikkeling van unieke plaaslike tegnologiese produk- en/of prosesvernuwings lei.

Die bou van 'n tegnologiese grondslag in 'n land verg dus dat alles moontlik gedoen word om die benutting van 
tegnologie te bevorder, om sodoende as aansporing te dien vir die uitbouing van tegnologiese vermoëns.

Die vermoë om die tegnologiestelsel en -benutting te bestuur, is van deurslaggewende belang. Sodanige bestuur van tegnologie behels bestuur deur alle rolspelers gesamentlik op landwye vlak, en die bestuur van tegnologie binne elke individuele organisasie en onderneming. Tegnologiebestuur behels veral strategiese ontleding (van doelwitte, sterk en swak punte, geleenthede en bedreigings), strategiese besluite (veral oogmerke en aksieplanne), asook die implementering en evaluering van die sukses van strategiese planne.

Die vier belangrikste elemente waaraan dringend aandag gegee moet word om die Suid-Afrikaanse tegnologiestelsel te verbeter, is dus befondsing vir wetenskap en tegnologie, wetenskaplike en tegnologiese mannekrag, tegnologiebestuur en -gesindheid, en onderlinge samewerking en koördinering tussen alle belanghebbendes om gesamentlik hierdie doelwit te verwesentlik.

Wat befondsing betref, is dit duidelik dat Suid-Afrika se owerheids- én sakesektor onderbestee aan wetenskap en tegnologie. Hoewel almal bewus is van die toenemende geldelike eise wat deur die nuwe Suid-Afrika aan die owerheidsektor gestel word, en van die kontantvloeiprobleme van groot dele van die sakesektor, is dit ook noodsaaklik dat geld in die wetenskap en tegnologie belê word om die grondslag vir toekomstige ekonomiese groei te vorm.

Dit is jammer dat ons vanweë omstandighede, en ook ons eie optrede in die verlede, nie vroeër begin het om in hierdie belangrike veld te belê nie, veral toe ons nog voordeel getrek het uit goud- en ander kommoditeitspryse wat aansienlik hoër was as wat tans die geval is en as wat vir die afsienbare toekoms voorspel word.

Die gebiede waar beleggings gemaak moet word, sluit in die opbou van basiese wetenskaplike en tegnologiese vaardighede en vermoëns, die dringende uitbouing van toegang tot internasionale bronne van tegnologie en wetenskap, en die behoud en aanvulling van toerusting en fasiliteite.

Die befondsingsituasie is tans ver van dié ideaal verwyderd. Daar is tans aansienlike geldelike besnoeiings ten opsigte van wetenskap en tegnologie, waarskynlik ooreenkomstig die algemene kortsigtige patroon (ook elders in die wêreld bevind) dat beleggings (soos wetenskap en tegnologie) wat slegs langtermynopbrengste bied, eerste gesny word in tye van geldelike nood. In die owerheidsektor het die besnoeiings byvoorbeeld etlike staatsdepartemente se besteding aan kontraknavorsing gesny.

'n Land se wetenskaplike en tegnologiese vermoëns is uiteraard afhanklik van sy geldelike vermoëns en van die beskikbaarheid van geskikte wetenskaplike en tegnologiese mannekrag, maar word veral bepaal deur die prioriteit wat wetenskap en tegnologie geniet. In Suid-Afrika sal dus al hoe meer aandag gegee moet word aan die doelmatige invloei en aanpassing van buitelandse tegnologie, gekoppel aan die doeltreffende oordrag hiervan na gebruikers - sowel plaaslik as in naburige lande.

Die klem op die benutting van tegnologie en die doeltreffende bestuur van die tegnologiese stelsels, insluitend behoorlike rolvervulling deur en goeie wisselwerking tussen die deelnemers in die owerheids- en sakesektor (veral die groot ondernemings), is van wesentlike belang. Daar moet doelmatige onderwys en opleiding wees; en balans tussen generiese en plaaslike tegnologieë, tussen wetenskap en tegnologie, tussen aanwendings van tegnologie in produksie en infrastruktuur, en tussen individuele streke.

Hierdie duidelike rigtingwysers word egter grotendeels geignoreer. Pleks van ons besteding aan wetenskap en tegnologie geleidelik te verhoog, val die klem tans op owerheidsbesnoeiings, en die verdere inkorting van geldelike aansporing vir privatesektortegnologie.

Pleks van die skaars wetenskaplike en tegnologiese mannekrag te behou en aan te vul, is daar tans afdankings sonder inagneming van nasionale langtermynbehoeftes; rasionalisering van opleidingsfasiliteite pleks van aansporings vir optimale benutting van dié fasiliteite; onvoldoende aansporing vir wetenskaplike en tegnologiese "immigrasie"; ontoereikende mannekragbeplanning (met gevolglike oorof ondervoorsiening op bepaalde wetenskaplike en tegnologiese terreine), asook minimale bevordering van wetenskap en tegnologie op skoolvlak.

Tegnologie is die enigste standhoudende bron van ekonomiese groei, ook vir Suid-Afrika, en talle lande doen alles binne hulle vermoë om die volle voordeel uit tegnologie en wetenskap te verkry. Aangesien ons selfs in ons interne markte al hoe meer met hierdie lande sal moet meeding, ontstaan die vraag of ons werklik die wil het om nou die regte stappe te neem om die Suid-Afrikaanse wetenskaplike en tegnologiese stelsel reg te stel en uit te bou om as grondslag te dien vir ons land se toekomstige welvaart.

J.B. CLARK 


\section{Die Suid-Afrikaanse Raad vir Natuurwetenskaplikes - een dekade later}

Die indiening van die Wet op Natuurwetenskaplikes (Wet 55 van 1982) is deur uiteenlopende standpunte en emosionele beredenerings in die wetenskapsgemeenskap gekenmerk. Vandag, een dekade later, is 'n kliniese en neutrale ontleding van die debatte van daardie tyd moontlik, en in die huidige klimaat besonder gepas. Voorstanders van die Wetgewing in 1982 se standpunte het hoofsaaklik om drie motiewe gesentreer. Eerstens het die breë massa natuurwetenskaplikes SARN as 'n eiebelang vakbond gesien; tweedens was daar 'n leierskorps van natuurwetenskaplikes wat SARN gesien het as 'n wetlike liggaam waardeur 'n wye persoonlike invloed in die wetenskapsgemeenskap verkry sou kon word, en derdens was daar die puriste wat deur wetenskapsbevordering gemotiveer was om die wetgewing te bevorder.

Aan die opposisiekant was daar ook drie duidelik identifiseerbare groepe. Eerstens was daar spesifieke belangegroepe binne die universiteitsgemeenskap wat die wetgewing, ook uit 'n eiebelang oogpunt, as 'n bedreiging vir die sogenaamde "akademiese vryheid" gesien het. Dan was daar die werknemersektor (sowel die Staatsdienskommissie as privaat werkgewers) wat die vakbondpersepsie uit eiebelang as 'n bedreiding gesien het. Laastens was daar ook enkele (miskien 'n handvol) wat getwyfel het of die wetenskaplikes werklik 'n professie uitmaak. Eienaardig genoeg was laasgenoemdes dié persone wat tydens die Parlementêre Debat die Wet moes debatteer en uiteindelik passeer. Dit is inderdaad ironies dat laasgenoemde nie deur eiebelang beïnvloed is nie en dat hulle bespreking die kern van die bestaan van SARN aangespreek het. Die ander belangegroepe begin nou eers, ongelooflik soos dit mag klink, die volle oogmerke van die Wet verstaan.

As natuurwetenskaplikes is ons nie uniek in dié aspek nie, trouens die werklike nasionale debat oor wetlike registrasie of institusionele registrasie begin nou eers in die Amerikaanse geologiese gemeenskap posvat, bykans 20 jaar nadat wetlike registrasie reeds in sommige state bestaan. Hierdie debat sal, wanneer die hersiende Konsepwet ten opsigte van SARN wat vanjaar in die Parlement sal dien, bespreek word, ook in die natuurwetenskaplike gemeenskap gevoer moet word. Die beginsels van 'n kompromie tussen die twee standpunte is grootliks in die Konsepwet beliggaam. Die vraag wat dikwels gevra word is wat het Wet 55 van 1982 vir die naturwetenskaplikes meegebring? Om die vraag te beantwoord is dit nodig om die indiensnemingspatroon van wetenskaplikes in 1982 in oënskou te neem. Bykans 100\% van alle wetenskaplikes was in daardie stadium werknemers van privaat maatskappye, universiteite of die staat (staatsdiens of parastatale instellings). Wetenskaplike kennis, produkte en dienste is beskou as van geen kommersiële waarde nie, en dit was die reg van die wellike professies (medici, ingenieurs, regslui ens.) om in die "gratis" produkte, vir eie gewin, handel te dryf. Trouens, die bestaan van wetlike professies wat natuurwetenskaplikes uitgesluit het, het dit vanweë werksreservering 'n kriminele oortreding vir natuurwetenskaplikes gemaak om in produkte en dienste handel te dryf.
Wet 55 van 1982 het, vanweë die wedersydse erkenning van opleiding en ondervinding tussen professies, die gelykberegtiging vir natuurwetenskaplikes geskep. Hierdie "ruimte" het oor die laaste dekade die publieke aanvaarding gevestig dat wetenskaplike kennis, dienste en produkte kommersieel verhandelbare produkte is. Dit het natuurwetenskaplikes voorts in staat gestel om raadgewende firmas te skep en het die wetenskappe in 'n ware professie verander.

Indirek het die kommersialisering van die wetenskap die parastatale instellings, onder die leiding van die WNNR, van staatsinstellings na besighede verander. Dit het indirek gelei tot die skepping van raamwerkoutonomie vir museums, parastatale instellings en die skepping van die Landbounavorsingsraad. In enkele professies het die bestaan van Wet 55 van 1982 ook 'n ongekende groei in raadgewende maatskappye tot gevolg gehad, en daar is tans byna geen natuurwetenskaplike professie waarvoor sodanige konsultfirmas of konsultante nie reeds in die privaat praktyk bestaan nie.

Die gevolg hiervan is 'n afname in die persentasie natuurwetenskaplikes binne die staats- en industriële sektor en 'n toename in wetenskaplikes wat 'n eie besigheid bedryf. Baie pasgegradueerdes wat tans nie vaste betrekkings kan bekom nie, maak toenemend 'n lewe as konsultante. Hierdie neiging dra dus daartoe by dat wetenskaplike dienste en produkte toenemend aandag skenk aan gemeenskapsbehoeftes en nie isoteriese doelwitte navolg nie, en dat hierdie vaardighede nou gerat is om wetenskaplike dienste en produkte binne Afrikaverband, asook internasionaal, teen vergoeding te lewer.

Toenemende kommersialisering van wetenskaplike dienste en produkte het ook bygedra tot 'n diversifikasie van dienste en produkte om toenemende gemeenskapsbehoeftes te bevredig. Hierdie professionalisme skep ook sosiale aanspreeklikheid vir die natuurwetenskaplikes teenoor die gemeenskap. Standaarde, etiese optrede en verpligtinge teenoor 'n gemeenskap wat nie deeglik in die wetenskap onderlê is nie, vereis dus vrywillige sertifikasie van bevoegdheid en waarborge vir kliëntesatisfaksie aan die gemeenskap. Registrasie van SARN wat implisiet bevoegdheid en kliëntesatisfaksie waarborg, is die sertifiseringsmeganisme vir die kliënte wat kwaliteitsdienste wil bekom. Die wetlike reservering van werk om die publieke belang te beskerm en wat inherent mededinging en die vrye mark beperk, word toenemend onaanvaarbaar en gevolglik word hierdie aspek in die nuwe wetgewing aangepas om by die vrye mark aan te pas. Die vrye mark werk normaalweg baie goed om die publiek te beskerm, mits die publiek 'n vrye keuse het en mits produkte en dienste gesertifiseer word.

Hierdie evolusie van SARN oor die laaste dekade het nou die punt bereik waar, om mededinging te verhoog, sertifikasie na tegnici, tegnoloë en B.Sc.-gegradueerdes uitgebrei word. Enersyds is sodanige gekwalifiseerdes 'n integrale deel van natuurwetenskaplike professies, en andersyds is gelykberegtiging vir die professies ten opsigte van ander tegnoloë noodsaaklik. Hierdie verwikkeling, wat in die 
nuwe SARN-wet beliggaam is, skep dus unieke geleenthede. Enersyds verhoog dit mededinging, verbreed dit die professies en skep dit 'n simbiose tussen tegnici en wetenskaplikes, sodat die professie toenemend 'n volledige diens aan kliënte kan lewer.

Die toenemende noodsaaklikheid om besluitneming oor en befondsing van dienste soos bv. onderwysdienste op gemeenskappe af te wentel, maak dit ook toenemend noodsaaklik dat sertifisering in die kategorieë moet bestaan om ouergemeenskappe 'n keuse te bied. Wiskunde-, wetenskap-, biologie-en aardrykskundeonderrig, die voorwaardes vir toekomstige welvaartskepping in die Republiek van Suid-Afrika, is dus gebiede waarbinne SARN sertifisering sou kon vestig om gemeenskappe wat dit sou verkies, in staat te stel om standaarde te handhaaf. Indien die algemene Afrikapatroon hom in die Republiek van Suid-Afrika herhaal, sou ouers en studente, kliënte van onderwys- en universiteitsdienste, ook die sertifisering kan benut om standaarde te handhaaf en kliëntesatisfaksie te eis.
Vir die standaarde wat die Republiek van Suid-Afrika in die toekoms sal moet handhaaf, het SARN betyds gekom en is die noodsaaklike aanpassings betyds gemaak om die professie te vestig. Die eiebelang oogmerke van die partye wat in 1982 gegeld het, is as ongegrond bewys. Natuurlik het dit ontnugtering by van die belangegroepe veroorsaak, maar ten misnte is die natuurwetenskaplike professie hierdeur gevestig.

Aan die vooraand van groot veranderinge in Afrika, die RSA inbegrepe, word dit duidelik dat die SARN-sertifisering in die kritieke wetenskapsveld, waarskynlik die inwerkingstellingsmeganisme sal wees om standaarde in SuidAfrika te bevorder. SARN het dus bewys dat inmenging in akademiese vryheid, bevrediging van persoonlike ambisies en die skepping van 'n spreekbuis vir wetenskap, niks met die professie te make het nie en dat die persepsies van oogmerke radikaal van die werklike oogmerke verskil.

C. FRICK 